\title{
Working with mass and light: A challenge for architecture students
}

\author{
Diana Giurea $^{\text {la }}$, and Cristian Blidariu ${ }^{1}$ \\ ${ }^{1}$ Faculty of Architecture and Urbanism, Politehnica University of Timisoara, Timisoara, Romania
}

\begin{abstract}
The distinctiveness of architecture education raises understanding issues and adaptation difficulties of first-year architecture students because of the abstract visual language they must become familiar with. Thus, a special attention should be given to the way in which the basics of architectural language are taught and implemented in particular design projects. The aim of this research is to test the efficiency of an intuitive-based didactical method through a specific design exercise. Therefore, in order to facilitate the shift from concrete elements to abstract ones we propose an exercise which will enable architecture students to design high-quality interior spaces. Starting from a personal space, each student will develop his/hers environment according to natural light needs, functional necessities and spatial relations between three main interior places, while working with an imaginary stone mass on which only subtractive operations are allowed. The illustrative part of the paper contains some of the students' work that we consider to be successful responses to the proposed exercise. This type of teaching method can trigger students' creativity by using only means which the students are already accustomed with: looking, searching and analyzing. Keywords: Architecture students, mass, light.
\end{abstract}

\section{Introduction}

The need to study the architectural form is defined by the major changes occurring in the current anthropic environment through a variety of socio-cultural phenomena and interconnected processes. Diversity and differentiation are the main features of this environment [1] found in a continuous process of change and, thus, the recalibration of the built environment plays a crucial role. This has led to the need to think and act creatively and innovatively according to the new parameters. The architect now has the task of providing high performance solutions capable of meeting this level of complexity. Accordingly, architectural form should provide an answer to many problems whose causes will be sought in the changes in contemporary society, environmental conditions, technological progress, etc.

a Corresponding author: diana.giurea@yahoo.com 
In Romania, the vast majority of people live in homes without architectural qualities, such as collective housing units intensively emerged during the communist period [2]. This type of buildings is characterized by standard living spaces built with regards to achieving high performance in economical and functional terms, but low attention to user's space experience and to his/hers real needs. This has led to a misconception of what architecture is and what can be achieved through it, constantly altering the way its inhabitants, including architecture students, perceive their surrounding built environment.

The task of architecture education, especially in the first year of studies, is to provide an experimental and effervescent environment able to stimulate the imaginary power of individuals and to establish the foundations of architectural language in students' conscience. The difficulty of managing this process is experienced beginning with the first year of study because each student has a certain amount of knowledge and experiences that can influence substantially their performance during the education period and in architectural practice. This paper tries to identify to what extent previous experiences can affect the creative performances of the architecture students.

The assimilation of a language does not always start with learning initial letters, but with perceiving its specific sounds. In architecture, the discussion is about the formal language whose alphabet is made up of the primary elements in which it can be decomposed [3]. But which is the counterpart of sound in architecture? It can be stated that the experience itself is the answer - a process by which the individual perceives the characteristics and general nature of the architectural object through physical referencing and in the light of previous experiences that may limit or intensify his/hers perception. The specificity of this present study consists in its focus on experience, where experience presumes movement in time and space such as in the case of the concept of burrow [4].

The didactic approach in this study uses a design experiment which proposes the return to the foundations of systems of thinking specific to man's primitive dwellings (Fig. 1) by imagining a situation that has only raw building material and one modeling tool. The choice of such a circumstance is explained by the low level of complexity of the material and its means of operation.

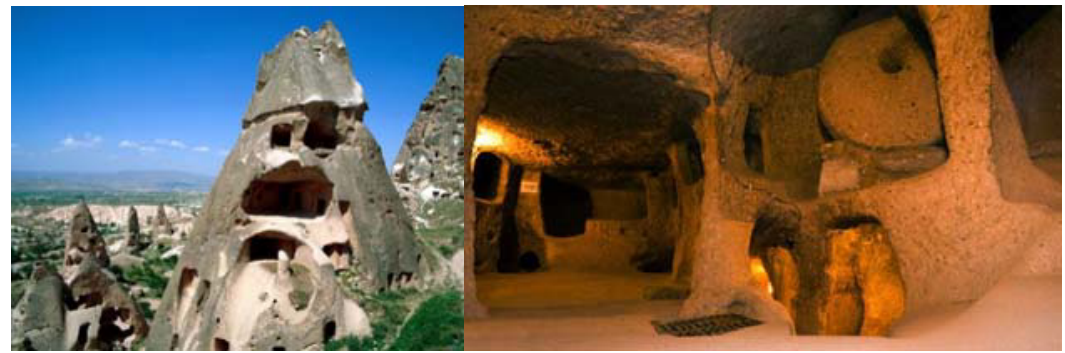

Fig. 1. Primitive dwellings in Cappadocia, Turkey

\section{Aims and objectives}

The main purpose of the proposed experiment is to test the influence of the background of first year architecture students, semester 1, on their imaginative abilities and the extent to which perceptive stimulation is capable to shape skills of detachment from the context in which they developed as individuals. The purpose is to develop a flexible thinking system that will ensure the transition from concrete components taken as they are to the specific formal abstracted language of architecture. To achieve this goal, we used a teaching method based on intuitive processes related to their own experience that, as Christopher Budd remarked, could stimulate the novelty, and the understanding of feelings and meanings [5]. 
Andrew Roberts estimated that individuals who tend to practice successfully intuitive thinking manage to see the big picture, in a holistic manner [6], an approach which is desirable in the architectural field. In this regard, the experiment "Working with mass and light" was born, aiming to provide students with the opportunity to express themselves creatively in their own space by increasing the spatial qualities using a single constructive material and a unique way of operating - subtraction. This experiment contains a number of objectives which participate in determining the influence the background of each student has on his/her formal expression means, such as: the definition and operation with a unitary formal language, the development of a imaginative three-dimensional thinking, the expression of differentiation by unity, the ability of correct dimensioning and spatial configuration according to the needs, etc.

\section{The design experiment "Working with mass and light"}

The experiment's starting data relates to the types of spaces where students spent most of their existence, space that has more or less left its mark on their perception of what architecture is, its composition and operating means. Thus, a survey was conducted on a number of 98 students, which revealed the following:

- 72 students live in urban multi-unit housing apartments built during the communist era, characterized by minimal and standardized spaces;

- 18 students live in urban single-family houses built during the post-revolution period (after 1989), an architecture characterized by resuming largely to functionalist and economic features of the collective dwellings described above;

- 8 students live in rural single-family homes, homes with low levels of interior comfort, but with access to a large outdoor space.

As an overview, the experiment consists of two major parts, structured in stages: analysis and implementation. The first part consists of three phases that will provide the base information for the design process. Starting from a perceptive analysis of the architectural elements with regards to the five senses (hearing, sight, touch, smell, taste), the student will focus on in-depth understanding of the specificity of personal space. In addition, he/she will try to familiarize him/herself with the notion of natural light and its effects on the perception of the character of interior spaces. The second part refers to the application of these information in the design of an architectural multispatial ensemble similar to the "burrow" type habitat, as it appears in the vision of Rudolf Arnheim [4].

\subsection{The perceptive analysis of the architectural elements}

The first stage of the experiment involves exploring the city of Timisoara in terms of the five senses, a process focused on identifying contrasts between various elements of the built environment, for example: vertical / horizontal, silence/noise, textured/plain, new/old, bright/dark, etc. This involves training thinking towards synthesizing visual information by three conscious actions: looking, searching and capturing. The anthropic environmental component analysis phase aims to establish the nature of architectural objects, but more importantly, the intuition of the means by which this character is defined. Furthermore, the student attempts to translate and interpret own feelings and experiences through the visual information extracted from the urban environment. It is worth mentioning that this is the student's first deliberate action of investigation and of understanding of parts which furnish urban space. 


\subsection{The analysis of personal space and the identification of its characteristics}

Once the previous stage passed, representing a first step in intuiting the qualities and the character of architectural objects, towards which the students did not previously displayed a particular interest, it felt natural for the next step to be the application of the knowledge gained in the previous phase on their own personal space. The selection of personal space as a subject has emerged from the idea that each individual has an interior space that he perceives as his, that "my room", a micro-universe populated by "my objects", "my atmosphere", "my activities" which defines that person's individuality.

The analysis manner of this space proposed to the students consists of determining its specific physicality and phenomenology. For example, by drawing the space's survey, the student will realize the influence of physical boundaries on perception and the possible presence of obstacles. On the other hand, the phenomenological analysis of the personal space is related to the relationship between actions and place. Preference for a particular area of personal space may be the result of spending a considerable time in that place or a predisposition to undertake various activities in a subarea of personal space. For example, the place of study may serve as a place to stay or socialize therefore the overall size is directly influenced by multifunctionality, by the objects that actively participate in these functions, but also by the physical and spiritual needs that involve some activities.

Thus, the information that the student acquires from the study will meet both quality data of space and his/hers favorite place, and a list of things he considers to be shortcomings, complemented by a series of goals that could participate in increasing comfort in terms of spatial experience.

\subsection{Natural light and the comfort of interior space}

Daily activities are directly influenced by the comfort offered by the interior space in which they take place. By eliminating all means of amplifying the interior comfort and quality of life (furniture, technology, ambient elements, etc.), regarded as functional and aesthetic additions, all that remains is space itself. But this space interacts with environmental phenomena. Of these, natural light plays an essential role in perceiving objects, spatial boundaries or directing movement and flow.

Of course light is not the only factor that leaves its deep mark on the spatial experience specific to architecture but, to avoid overloading with variable elements and simplifying the analysis process to a single phenomenon through reduction, step 3 of the experiment focuses on identifying the means of introducing daylight indoors, the effects of plastics that it can get through and, not least, the influence exerted by this user's behavior in terms of spatial experience. The requirement for this phase is to look for examples of indoor natural light that actively participate in defining recognition along with their impact on spatial perception of the user.

\subsection{Augmenting the reality of personal space}

All information collected in the steps listed above, together with the theoretical part, represent working tools for advancing to the creative phase of the approach. The emphasis is on the individual and his/her quest to identify own needs, and the shortcomings arising from the interaction with personal space that will turn into something embedded into the project imagined. 


\subsubsection{The context}

Starting from John L. Culkin's idea according to which "We shape our tools and therefore our tools shape us" [7] we can already see that the world consists of objects and phenomena, that we see the world concretely both through sight, hearing, smell, touch, and sensitively, based on experience and subjective interpretations of these experiences. Architectural space is both objective and subjective because it is built by what French philosopher Michael Foucault called the prosthetic god, that is, a man endowed with tools and technology. "Gods" have shaped the natural world, people have anthropized it by tools. A man maneuvering a hoe, a hammer, a chisel extends his will through the prosthetic tool. The chisel becomes an extension of the arm, just like today smartphones are becoming auxiliary organs of the mind. How many of you have not felt incomplete, cut off from the world, in its accidental absence? This is the power of tools. They transform us.

Equipped with tools that have enhanced his abilities, man transformed the world according to his measurements, has conquered and mastered it. Architectural space is thus a measure of man but also of these tools. As a consequence of these very tools, homes today are different from homes dating one hundred years ago, just as they in turn are different from homes dating a thousand years ago, and, regressing to the beginning of history, from the first caves occupied by man. Spatial archetypes however have remained unchanged because personal space has retained its functions: protection against the elements, protection against others, and a meeting place with them, place of individual study and reflection, as well as of hosting and receiving. Each of us wants to build this space according to our own desires.

\subsubsection{Design assignment}

The assignment puts the student in front of his/her own space. Until now, space was presented through words and objects, and dimensions it revealed. The student studied the qualities of spaces, saw how these spaces can interfere by tangents and overlaps, and had observed the qualities they acquire through light. Next he/she will use all these elements analyzed to redefine the room in an ideal representative variant. To do this, the student will start from his/her room's dimensions. It will be considered as the support-empty space around which he/she will have to redeploy a given built mass so as to generate subspaces and places only within this new material. The amount of mass that can be used and distributed around this given space cannot exceed six times the air volume of the existing room. In these new spatial limits with variable thicknesses, the requirement is to generate a place to sleep, a place to study and a place with a function to be chosen by each student according to own needs. The current capacity of the room shall remain recognizable until the end and can be formally changed only up to a maximum $25 \%$. It will remain as a distribution and meeting space, a semi-public area to which other spaces are attached. The material making up the mass is rock. It can be built in blocks of different sizes or excavated from a single block. The tool will be the chisel. In spatial positioning, the student will have to operate with natural light and with light gap marks left both on the outer surface area (facade) and on the inside. The student will have to determine how one enters this space, what is seen and unseen, and if this process is an experience in itself.

\subsubsection{Evaluation criteria}

The evaluation criteria of the projects are designed to measure the levels of attainment of the objectives by each project. The main issues that have influenced the appreciation of final proposals were: 
- creating a cursive and consistent spaciousness;

- the ability to interpret and generate a clear expression in a space;

- understanding the relationship between the excavated void and mass seen as a cover;

- the ability to negotiate in the same formal language with spaces with different functions;

- treating the epidermis as a mediator between the inner and outer space in the relation to the conditions of penetration of natural light and understanding the role the cover plays;

- the relationship between space, material and texture;

- clarity of concept expression by means of graphic and layout drafting.

Depending on the degree of fulfillment of these criteria, the projects relate to the minimum locative character from which the study started; by compared, we established whether the project has managed to overcome the "burrow" type organization through a complex spaciousness shaped according to wishes and needs.

\section{Findings and results}

Following the evaluation of the projects drawn, we have considered as positive responses to the experiment undertaken only 38 of the 95 works handed-in. Each of these has managed to fulfill most of the evaluation criteria stipulated above. Formally, there is a number of variables that participated in customizing each project, resulting in works that use various elements of more or less uniform architectural language. The main factors responsible for the differentiation and influence exerted by them on projects are listed in the Table 1.

Table 1. Variables and effects

\begin{tabular}{|c|c|c|}
\hline Variables & & Effect \\
\hline $\begin{array}{r}\text { Initial personal space dimensions and } \\
\text { volume }\end{array}$ & $\rightarrow$ & $\begin{array}{l}\text { Increase or decrease of the maximum of } 6 \\
\text { times mass addition }\end{array}$ \\
\hline $\begin{array}{r}\text { The proposed function of the new interior } \\
\text { spaces and } \\
\text { connection means }\end{array}$ & $\rightarrow$ & $\begin{array}{l}\text { According to the activities which would take } \\
\text { place in that space, the overall size and } \\
\text { interior configuration }\end{array}$ \\
\hline Student personal preferencies & $\rightarrow$ & $\begin{array}{l}\text { Vertical or horizontal project development, } \\
\text { different types of introducing natural light in } \\
\text { interior spaces }\end{array}$ \\
\hline $\begin{array}{r}\text { Quality and means of drawing and } \\
\text { representation }\end{array}$ & $\rightarrow$ & $\begin{array}{l}\text { The project is / is not easy to understand and } \\
\text { is/is not }\end{array}$ \\
\hline $\begin{array}{r}\text { Guidance and discussions with two } \\
\text { teachers, alternatively }\end{array}$ & $\rightarrow$ & $\begin{array}{l}\text { The student tries to understand and apply } \\
\text { into hir/hers project all the information } \\
\text { gathered durring the discussions - a process } \\
\text { which can be more or less accurate }\end{array}$ \\
\hline
\end{tabular}

It should be noted that the nature of the variables is found at different levels: variables related to actual data of the design assignment, preferences and imaginative capabilities of the student, and, not least, the type of guidance given by teachers and the understanding and assimilation of the aspects discussed during a project correction.

The images below depict some examples of the students' works (Figure 2) developed in this exercise that we have considered to be positive responses to the great complexity of the design assignment. As it can be seen, representation was left up to each student, which has highlighted even more the individuality of each project. Materials used for the layout and the operating technique represent the students' personal option, with the mention that the final result should be consistent with the drawn pieces and the general nature of the project. 


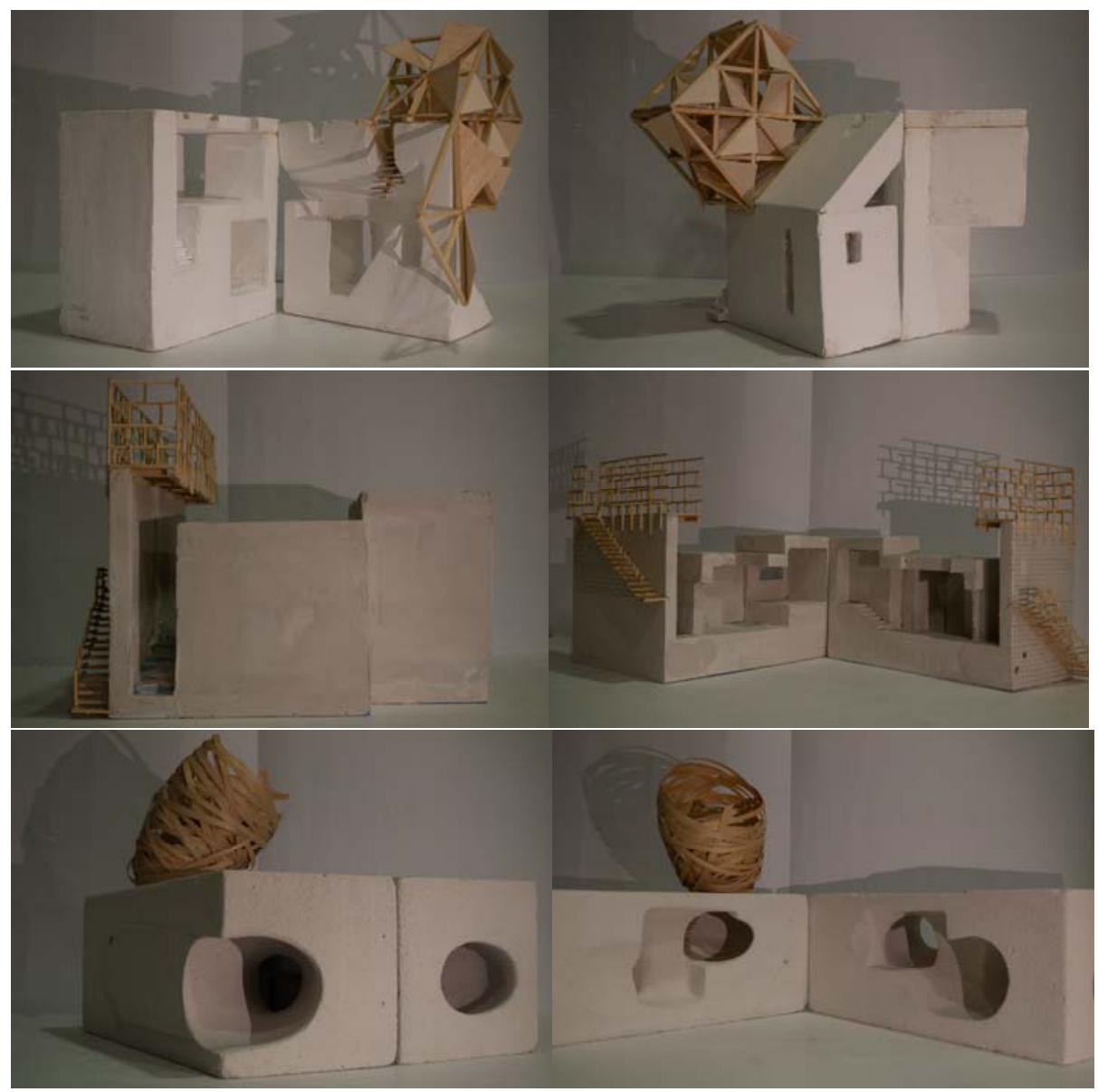

Fig. 2. Student work

This experiment however does not related to the architectural object resulted, but to testing the influence a student's previous experience can have on his/her imaginary and abstraction capability. The 38 projects evaluated positively relative to the current habitat of each architecture student translate numerically as follows:

-36 projects were developed by students who live in apartments in standardized collective dwellings;

-1 project belongs to a student living in an urban single-family home built in the early ' $90 \mathrm{~s}$;

-1 project was created by a student who lives in a rural modest single-family home.

It should be noted that if the two first categories of projects focused on interior space and the outer configuration remained parallelopipedic, for the third case increased attention to the expression of the interior space to the outside figure of the massive was observed.

\section{Conclusions and recommendations}

In conclusion, we believe that this intuitive-cognitive approach of the educational process in architecture for first year students can be considered a viable alternative to stimulate students' capacity for abstraction, a preamble in learning the architectural language's alphabet. The results confirm that the environment in which an individual carries out 
his/her daily existence can influence the perception on architectural spatial experience but not in an irreversible manner, as evidenced by the 38 positive results obtained in the experiment "Working with light and mass" which managed to exceed their possible limitations caused by the indoctrination produced by purely functionalist architecture and dictated by socio-economic factors.

In addition, it should be noted that the last project draws attention to the importance of access to the outer space for understanding the needs of external perceptual experiences in relation to the interior ones. From a teaching perspective, in order to improve outcomes for this type of exercise, we recommend the following:

- Ensuring the theoretical study necessary for each stage by outlining the elements of architectural language, concepts, focusing on the presentation of relevant case studies;

- In developing a design assignment, enunciation of data in the design assignment must consider presenting a clear framework for the conduct of the study;

- Increasing fixed character requirements and decreasing variable elements, where the latter will eventually focus on the means of architectural expression;

- Emphasizing the importance of dialogue between content and container, that is, in this case, mass and interior space;

- Considering the fact that in general design workshops in architectural education imply an extended collective of teachers, in which each member has certain preferences and sensitivities, we propose that revision sessions to alternate between revisions made by only one teacher with sessions with more teachers to establish common guide denominators;

- Developing a questionnaire able to reveal the quality of the backgrounds of each student.

\section{References}

1. F. Moussavi, The function of form. Cambridge, SUA: ACTAR, Harvard Graduate School of Design (2009)

2. C. Culiciu, Romanian cities and socialist urbanism. consequences on the aspects of the cities and on everyday life. In From post-industrial to an information society, Rzeszow: University of Rzeszow. p.39 (2015)

3. F.D. Ching, Architecture: form, space and order. Hoboken: John Wiley \& Sons, Inc. (2007)

4. R. Arnheim, The dynamics of architectural forms. Berkeley: University of California Press, p.148 (1977)

5. C. Budd, Valuing the Intuitive: Reintroducing Design Into Interior Design Education. Journal of Interior Design, 36, 3, v-xi (2011)

6. A. Roberts, Cognitive styles and student progression in architectural design education. Design Studies 27, 161-181 (2006)

7. J.L. Culkin, A Schoolman's Guide to Marshall McLuhan. The Saturday Review , 51-53 (1967) 